Vol. 23, No. 2, September 2020, hlm. 129-140

p-ISSN: 1410-9344; e-ISSN: 2549-5631

homepage: http://journals.ums.ac.id/index.php/warta

\title{
Penggabungan Sekolah Dasar Negeri di Kabupaten Kendal Menuju Pengelolaan Pendidikan yang Efisien
}

\author{
Muhdi, Nurkolis Siri Kastawi , Yovitha Yuliejantiningsih, Sunandar \\ Program Studi Manajemen Pendidikan \\ Universitas PGRI Semarang \\ email: nurkolis@gmail.com
}

\begin{tabular}{l}
\hline \multicolumn{1}{c}{ Article Info } \\
\hline Submitted: 15 January 2020 \\
Revised: 22 February 2020 \\
Accepted: 20 March 2020 \\
Published: 7 April 2020 \\
Keywords : school regrouping; \\
education management; \\
education efficiency; small \\
school; national standard school.
\end{tabular}

school; national standard school.

Kata Kunci : penggabungan sekolah; pengelolaan pendidikan; efisiensi pendidikan; sekolah kecil; sekolah standar nasional.

\begin{abstract}
Kendal District covers 20 sub-districts has 551 Public Elementary Schools (SDN). The total number of teachers is 5,452 consisting of 3,471 class teachers, 1,410 subject teachers, and 571 school principals. Many SDNs lack of students and many teachers do not meet the teaching load. This resulted in the inefficient implementation of education. The purpose of this activity is to find out: (a) the condition of SDN, (b) the condition of teachers in SDN, and (c) the efficiency of education management in SDN. Community service is carried out in three stages, namely the analysis of basic education data, the focused group discussion, and the discussion to gather to make regional policies on regrouping. The results show that: (a) the condition of the education unit is not evenly distributed because the majority (71\%) of SDNs is very small school categories (44\%) and small schools (27\%); (b) the condition of classroom teachers is over in 73\% of SDN and PNS teachers dominate of 66\%; and (c) SDN management has not been efficient in terms of student teacher ratios because $76 \%$ do not meet the rules, the ratio of classroom teachers to study groups is inefficient because 73\% of SDNs are over grade teachers, and as many as $21 \%$ of teachers have not worked according to regulations. Based on the results of this service, it is recommended that regulations be immediately passed to regulate the provision of more efficient education.
\end{abstract}
Abstrak
Kabupaten Kendal mencakup 20 kecamatan dan memiliki 551 SDN (Sekolah Dasar Negeri). Total guru di Kabupaten Kendal sebanyak 5.452 orang terdiri dari guru kelas 3.471 orang, guru mata pelajaran 1.410 orang, dan kepala sekolah 571 orang. Banyak SDN di Kabupaten Kendal kekurangan peserta didik dan banyak guru yang belum memenuhi beban mengajar. Hal tersebut mengakibatkan penyelenggaraan pendidikan tidak efisien. Maka tujuan kegiatan ini adalah untuk mengetahui: (a) kondisi satuan pendidikan di SDN, (b) kondidi guru di SDN, dan (c) efisiensi pengelolaan pendidikan 
di SDN. Pengabdian kepada masyarakat ini dilakukan dengan tiga tahapan yaitu analisis data pokok pendidikan, diskusi terpumpun untuk verifikasi dan penentuan sekolah yang digabung, dan diskusi terpumpun untuk membuat kebijakan daerah tentang penggabungan. Hasil pengabdian menunjukkan bahwa: (a) kondisi satuan pendidikan tidak merata karena mayoritas (71\%) SDN termasuk katetori sekolah sangat kecil (44\%) dan sekolah kecil (27\%); (b) kondisi guru kelas mengalami kelebihan di $73 \%$ SDN dan guru PNS mendominasi yaitu 66\%; dan (c) pengelolaan SDN belum efisien dilihat dari rasio guru siswa karena $76 \%$ belum memenuhi aturan, rasio guru kelas dengan rombongan belajar tidak efisien karena 73\% SDN kelebihan guru kelas, dan sebanyak $21 \%$ guru belum bekerja sesuai dengan regulasi. Berdasarkan hasil pengabdian ini disarankan untuk segera disahkan regulasi guna mengatur agar penyelenggaraan pendidikan di Kabupaten Kendal yang lebih efisien.

\section{PENDAHULUAN}

Permasalah utama pendidikan dasar di Kabupaten Kendal saatini adalah tidak efisiennya penyelenggaraan pendidikan. Penyebab utama tidak efisiennya penyelenggaraan pendidikan adalah banyaknya jumlah Sekolah Dasar Negeri (SDN) sementara itu jumlah peserta didik tidak proporsional jika mengikuti standar nasional pendidikan. Maka tujuan kegiatan ini adalah untuk mengetahui: (a) kondisi satua pendidikan di SDN, (c) kondisi guru di SDN, dan (c) efisiensi pengelolaan pendidikan di SDN.

SDN di Kabupaten Kendal banyak didirikan pada tahun 1975 ketika Pemerintah Pusat mendirikan SDN Inpres secara nasional. SDN Inspres itu sendiri didirikan untuk memenuhi kebutuhan pendidikan bagi anak usia sekolah SD yang jumlahnya besar. Anak usia SD yang jumlahnya besar menjelang tahun 1970an terjadi ledakan kelahiran bayi atau dikenal dengan istilah baby boom. Pembangunan SD Impres tersebut dilakukan oleh Badan Penelitian dan Pengembangan Pendidikan dan Kebudayaan (BP3K) berdasarkan Instruksi Presiden No. 10 tahun 1973 dan Instruksi Presiden No. 6 tahun 1974. Proses pembelajaran SD Inpres dimulai tahun 1975 dan pada tahun 1980 meluluskan siswa SD yang pertama kali (https://lenterakecil. com/sekilas-sd-inpres-dan-sekolah-pamong). Tidak ada laporan yang spesifik tentang kualitas SD Inpres di Kabupaten Kendal, namun di Kota Palu peningkatan kualitas SD Inpres sama dengan SD Negeri (https://indonesiainside.id/ news/nasional/2019/10/23/sd-inpres-duludan-kini-bagian-iii).

Tabel 1. Jumlah SD Negeri dan SD Swasta

\begin{tabular}{lcccc}
\hline Kecamatan & SDN & SDS & Jumlah & Prosen \\
\hline Boja & 40 & 2 & 42 & $7 \%$ \\
Brangsong & 25 & 1 & 26 & $5 \%$ \\
Cepiring & 28 & 0 & 28 & $5 \%$ \\
Gemuh & 26 & 0 & 26 & $5 \%$ \\
Kaliwungu & 23 & 0 & 23 & $4 \%$ \\
Kal. Selatan & 18 & 2 & 20 & $3 \%$ \\
Kangkung & 27 & 1 & 28 & $5 \%$ \\
Kota Kendal & 34 & 4 & 38 & $7 \%$ \\
Limbangan & 30 & 0 & 30 & $5 \%$ \\
Ngampel & 17 & 0 & 17 & $3 \%$ \\
Pageruyung & 30 & 0 & 30 & $5 \%$ \\
Patean & 32 & 0 & 32 & $6 \%$ \\
Patebon & 30 & 3 & 33 & $6 \%$ \\
Pegandon & 19 & 2 & 21 & $4 \%$ \\
Plantungan & 26 & 0 & 26 & $5 \%$ \\
Ringinarum & 19 & 0 & 19 & $3 \%$ \\
Rowosari & 27 & 1 & 28 & $5 \%$ \\
Singorojo & 36 & 0 & 36 & $6 \%$ \\
Sukorejo & 34 & 4 & 38 & $7 \%$ \\
Weleri & 30 & 3 & 33 & $6 \%$ \\
\hline Total & 551 & 23 & 574 & $100 \%$ \\
\hline Sumber & &
\end{tabular}

Sumber data: Diolah dari Dapodikdasmen, 2019. 
Sejak tahun 1991 angka kelahiran bayi di Indonesia terus mengalami penurunan karena keberhasilan program keluarga berencana (KB). Pada 1991 angka kelahiran bayi masih 3\%, tahun 1994 turun menjadi 2,9\%, tahun 1997 turun lagi menjadi 2,8\%. Penurunan angka kelahiran bayi terus terjadi pada 2002 hingga 2012 sekitar 2,6\%, dan tahun 2017 turun lagi hingga 2,4\% (https://www.alinea.id/nasional/bkkbn-trenangka-kelahiran-bayi-terus-turun-sejak-1991b1Uxv9W8).

Selain itu akhir-akhir ini bermunculan SD swasta dan Madrasah Ibtidaiyah (MI). Hingga saat ini sudah ada 23 SD Swasta (Dapodikdasmen, 2019) seperti tampak pada tabel berikut. Maka setelah tahun 2.000 banyak SDN yang kekurangan siswa.

Salah satu upaya yang dapat dilakukan untuk meningkatkan efisiensi penyelenggaraan pendidikan di Kabupaten Kendal adalah dilakukan penggabungan sekolah-sekolah kecil yang berdekatan, atau sekolah kecil dan sekolah besar yang berdekatan, atau sekolah besar dengan sekolah besar lainnya yang berada di dalam satu lokasi atau satu kampus. Menurut seorang ahli manajemen, penggabungan sekolah diperlukan karena tidak efisiennya manajemen sekolah seperti rasio guru dengan siswa kurang, beban kerja guru kurang, dan masalah distribusi guru yang tidak merata (Triwiyanto, 2017). Penggabungan sekolah perlu didukung dengan kebijakan pemerintah daerah untuk mengatasi masalah pendidikan terutama terkait efektivitas belajar mengajar (Dwiningrum dan Widiowati, 2014).

Untuk bisa melakukan penggabungan tersebut maka perlu dilakukan analisis kondisi SDN berdasarkan jumlah murid dan kondisi guru di masing-masing satuan pendidikan. Dalam analisis kondisi sekolah dikenal dengan sekolah kecil, sekolah standar nasional (SSN), dan sekolah standar pelayanan minimal (SPM). Sekolah standar pelananan minimal diartikan sebagai sekolah yang jumlah muridnya melebihi ketentuan yang diatur oleh pemerintah. Jika jumlah muridnya melebihi jumlah yang diatur dalam SSN justru dikategorikan SPM karena tidak efektif untuk mencapai tujuan pendidikan.

Menurut Bank Dunia sekolah dasar (SD) dengan 6 rombongan belajar yang memiliki peserta didik minimal 168 orang adalah sesuai dengan sekolah standar nasional dan sekolah dasar yang memiliki jumlah murid maksimal 192 adalah sekolah sesuai dengan standar pelayanan nimimal. Sementara itu sekolah kecil adalah sekolah yang jumlah muridnya kurang dari 168 orang (Bank Dunia, 2013).

Berdasarkan Data Pokok Pendidikan Dasar dan Menengah (Dapodikdasmen) Tahun 2019, dengan menggunakan terminologi Bank Dunia, jumlah sekolah kecil di Kabupaten Kendal ada 392 dari total 551 SDN. Sebanyak 71\% SDN di Kabupaten Kendal adalah sekolah kecil. Bahkan 244 dari total 551 (44\%) diantara adalah sekolah sangat kecil karena jumlah muridnya kurang atau sama dengan 120 orang.

Menurunnya jumlah penduduk di daerah pinggiran sebagai akibat keberhasilan program Keluarga Berencana (KB), faktor urbanisasi, dan persaingan dengan SD Swasta dan MI mengakibatkan banyak SDN yang kekurangan murid. Dalam kondisi demikian, maka salah satu solusi untuk mengelola pendidikan secara efisien dan efektif adalah melalui penggabungan. Hal tersebut telah dilakukan di beberapa kabupan di Jawa Tengah seperti di Kabupaten Sleman (Sudiyono, Sutapa, dan Purwanto, 2009: 355) dan Kabupaten Purworejo (Purwaningsih, 2014).

Menurut Keputusan Menteri Dalam Negeri Nomor 421.2/2501/Bangda/1998 tentang pedoman pelaksanaan penggabungan sekolah dinyatakan bahwa penggabungan SD adalah usaha penyatukan dua unit SD atau lebih menjadi satu SD dan diselenggrakan dalam satu pengelolaan. Pengertian senada tertuang dalam Kepmendiknas Nomor 060/U/2002 tentang Pedoman Pendirian Sekolah. Pada pasal 23 ayat (1) tertulis, pengintegrasian sekolah merupakan penggabungan dua atau lebih sekolah sejenis menjadi satu sekolah. Tujuan penggabungan SD adalah untuk mengatasi masalah kekurangan tenaga guru, peningkatan mutu, dan efisiensi penyelenggaraan pendidikan.

Pemerintah Kabupaten Kendal telah mengatur besaran jumlah peserta didik per rombongan belajar. Dalam Perda Pendidikan No. 4 Tahun 2018, Pasal 26 ayat (2) huruf b, tertuang bahwa perbandingan jumlah guru dan peserta didik pada SD atau satuan pendidikan yang 
setara tersedia 1 orang guru untuk setiap 20 (dua puluh) peserta didik dan enam orang guru untuk satu satuan pendidikan. Ayat (3) tertulis bahwa satuan pendidikan yang diselenggarakan Pemerintah dan/atau Pemerintah Daerah yang tidak memenuhi ketentuan sebagaimana dimaksud pada ayat (2) dan/atau karena alasan tertentu dapat digabungkan dengan satuan pendidikan lain yang sejenis. Hal ini tertuang pada Perda Pendidikan No. 4 Tahun 2018 tentang Perubahan atas Peraturan Daerah Kabupaten Kendal Nomor 10 Tahun 2012 tentang Pengelolaan dan Penyelenggaraan Pendidikan di Kabupaten Kendal.

Perda tersebut mengacu pada Visi Bupati Kendal 2016-2021 adalah "Terwujudnya Kemajuan dan Kesejahteraan Masyarakat Kabupaten Kendal yang Merata Berkeadilan Didukung oleh Kinerja Aparatur Pemerintah Yang Amanah dan Profesional Serta Berakhlak Mulia Berlandaskan Iman dan Taqwa Kepada Allah SWT". Untuk mencapai visi tersebut, ditempuh melalui 9 (sembilan) misi yang dua diantaranya terkait penyelenggaraan pendidikan adalah: (1) mewujudkan tatakelola pemerintahan yang demokratis, transparan, akuntabel, efektif-efisien, bersih, bebas KKN; dan (2) menciptakan sumber daya manusia yang cerdas, unggul, serta berakhlak mulia (Rencana Strategis Dinas Pendidikan Kabupaten Kendal Tahun 2016-2021).

Hal ini sesuai dengan Agenda Prioritas Pembangunan 5 (Nawacita 5) yaitu meningkatkan kualitas hidup manusia dan masyarakat Indonesia. Pada arah kebijakan dan strategi ke-7 adalah meningkatkan pengelolaan dan penempatan guru, melalui beberapa cara yang salah satunya adalah pengembangan kapasitas pemerintah kabupaten dan kota untuk mengelola perekrutan, penempatan, dan peningkatan mutu guru secara efektif dan efisien (Rencana Pembangunan Jangka Menengah Nasional Tahun 2016-2019).

Berdasarkan data dan latar belakar masalah di atas, maka rumusan masalah dalam artikel ini adalah: (a) bagaimanakah kondisi SDN di Kabupaten Kendal? (b) bagaimanakah kondisi guru SDN di Kabupaten Kendal? dan (c) bagaimanakah efisiensi pengelolaan SDN di
Kabupaten Kendal? Dengan demikian manfaat dari pengabdian kepada masyarakat ini adalah membantu Pemerintah Kabupaten Kendal untuk menyusun kebijakan penggabungan sekolah sehingga pengelolaan pendidikan bisa berjalan secara efisien.

\section{METODE}

Metode pelaksanaan pengabdian kepada masyarakat yang dijadikan sebagai dasar penulisan artikel ini dilakukan dengan tiga tahap. Selengkapnya dapat dilihat pada gambar 1 .

Medote pengabdian kepada masyarakat ini secara detail dapat diuraikan seperti di bawah ini. Pertama, Analisis Data Pokok Pendidikan. Dinas Pendidikan dan Kebudayaan memiliki data lengkap terkait persekolahan dan guru. Data tersebut disimpan di Data Pokok Pendidikan (Dapodik) yang setiap semester diperbaharui. Tim pengabdi berkoordinasi dengan operator Dapodik Dinas Pendidikan Kabupaten Kendal untuk mendapatkan data tersebut, lalu melakukan analisis, dan hasilnya dipaparkan untuk mendapatkan konfirmasi dari pihakpihak terkait di Sekolah, Kecamatan, dan Dinas Pendidikan Kabupaten.

Kedua, Focus Group Discussion atau diskusi terpumpun. Diskusi terpumpun ini untuk mempresentasikan hasil analisis data persekolahan yang isinya adalah sekolah-sekolah dengan jumlah murid kurang dari 20 orang per rombongan belajar. Diskusi terpumpun ini sekaligus untuk mendapatkan verifikasi kelayakan sekolah-sekolah tersebut untuk di gabung. Dalam diskusi ini juga dipertimbangkan agar penggabungan ini tidak menghalangi akses siswa/masyarakat untuk mendapatkan pendidikan.

Ketiga, perumusan draf kebijakan. Metode terakhir adalah penyusunan draf kebijakan yang akan mengatur secara legal penggabungan sekolah-sekolah kecil. Kebijakan yang akan disusun bisa berupa Peraturan Bupati (Perbub) atau Surat Keputusan (SK) Bupati tentang Petunjuk Teknis penggabungan sekolah. Setelah ada produk kebijakan ini, maka penggabungan dapat dijalankan. 


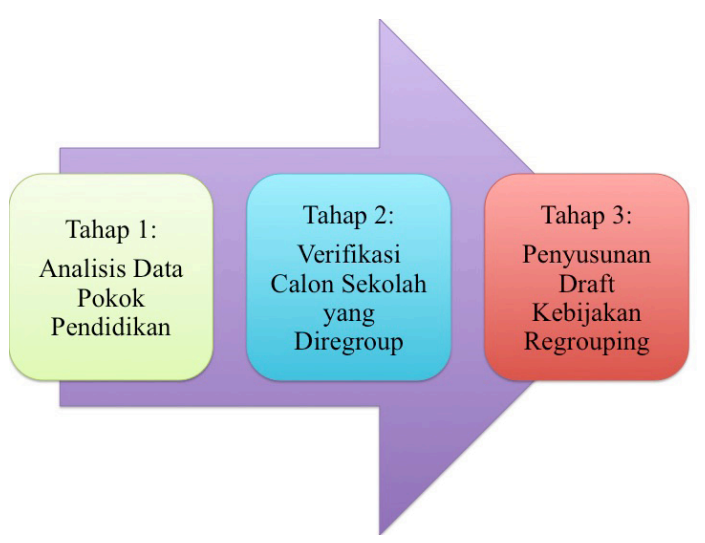

Gambar 1: Metode Pengabdian

\section{HASIL DAN PEMBAHASAN}

\section{Kondisi SDN di Kabupaten Kendal}

Kabupaten Kendal terdiri dari 20 Kecamatan dan memiliki 551 SDN. Dalam pengabdian kepada masyarakat ini kondisi sekolah diklasifikasikan menjadi 3 kelompok yaitu sekolah sangat kecil yang jumlah siswanya $\leq 120$ orang, sekolah kecil yang jumlah siswanya antara 121-168 orang, dan sekolah memenuhi standar nasional yang jumlah siswanya $>168$ orang. Data telah diferivikasi oleh Dinas Pendidikan Kabupaten Kendal pada saat koordinasi tanggal 09 Agustus 2019, seperti tampak pada gambar 2 .

Berdasarkan klasifikasi SDN, sebanyak 244 sekolah atau $44 \%$ termasuk ke dalam klasifikasi sekolah sangat kecil, sebanyak 148 sekolah atau 27\% termasuk ke dalam klasifikasi sekolah kecil, dan sebanyak 159 sekolah atau 29\% termasuk ke dalam klasifikasi sekolah standar nasional.

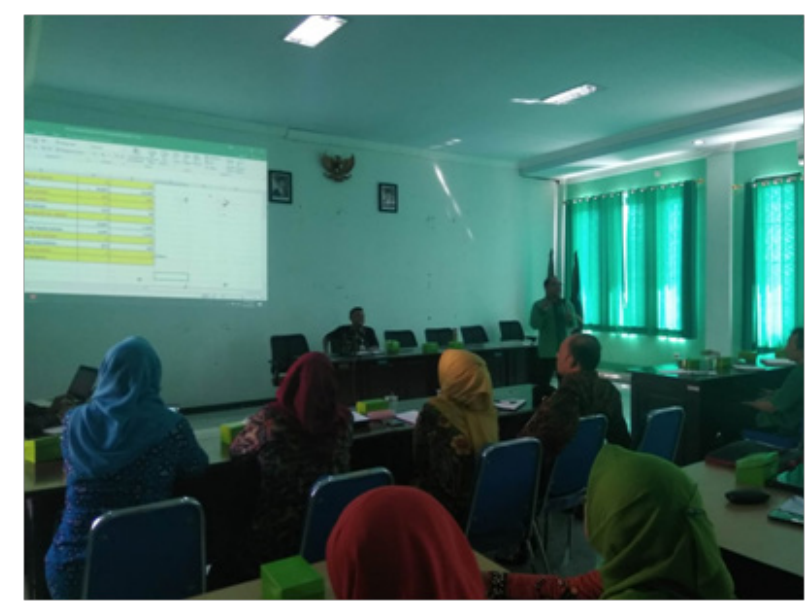

Gambar 2. Proses Verifikasi dan Penghitungan Reproping SDN
Lima kecamatan yang memiliki jumlah sekolah termasuk klasifikasi sekolah sangat kecil yaitu Kecamatan Kota Kendal (21 sekolah), Kecamatan Patean (21 sekolah), Kecamatan Plantungan (22 sekolah), Kecamatan Sukorejo (22 sekolah), dan Kecamatan Pageruyung (26 sekolah).

Sekolah sangat kecil bisa dikelompokkan menjadi dua berdasarkan prioritas penggabungan yaitu prioritas ke-2 dan ke1. Tabel tersebut dengan jelas menunjukkan banyaknya jumlah sekolah yang masuk kategori sekolah kecil dan sekolah sangat kecil yang perlu prioritas penanganan penggabungan agar penyelenggaraan pendidikan di Kabupaten Kendal bisa efisien.

Di Kabupaten Kendal terdapat 138 sekolah sangat kecil prioritas ke-2 yaitu jumlah murid 61-90 orang. Lima kecamatan yang memiliki jumlah sekolah dengan klasifikasi sangat kecil prioritas ke-2 yaitu Kecamatan Kota Kendal (12 sekolah), Kecamatan Sukorejo (14 sekolah), Kecamatan Limbangan (15 sekolah), Kecamatan Pageruyung (17 sekolah), dan Kecamatan Plantungan (19 sekolah).

Bahkan ada 37 sekolah yang jumlah muridnya $\leq 60$ orang yang menjadi prioritas ke-1 untuk digabung. Ada 5 kecamatan yang jumlah muridnya $\leq 60$ orang yaitu Kecamatan Patebon (3 sekolah), Kecamatan Limbangan (4 sekolah), Kecamatan Singorojo (4 sekolah), Kecamatan Pageruyung (7 sekolah), dan Kecamatan Plantungan (10 sekolah).

Enam kecamatan yang memiliki jumlah sekolah klasifikasi SSN adalah Kecamatan Bransong (10 sekolah), Kecamatan Kaliwungu Selatan (10 sekolah), Kecamatan Kota Kendal (11 sekolah), Kecamatan Cepiring (12 sekolah), Kecamatan Kaliwungu (18 sekolah), dan Kecamatan Boja (20 sekolah). Selengkapnya data sekolah di Kabupaten Kendal tampak pada tabel berikut. Berikut adalah gambar proses proses Verifikasi data dan penghitungan data sekolah yang akan digabung. 
Tabel 2. Rekapitulasi Sekolah Di Kendal

\begin{tabular}{lcccccc}
\hline \multirow{2}{*}{ Kecamatan } & \multicolumn{7}{c}{ Klasifikasi SDN Menurut Jumlah Murid } & \multirow{2}{*}{ Jumlah } \\
\hline Boja & $\mathbf{6 0}$ & $\mathbf{6 1 - 9 0}$ & $\mathbf{9 1 - 1 2 0}$ & $\mathbf{1 2 1 - 1 6 8}$ & $\mathbf{1 6 8}$ & \\
Brangsong & 1 & 3 & 5 & 11 & 20 & 40 \\
Cepiring & 0 & 2 & 3 & 10 & 10 & 25 \\
Gemuh & 0 & 1 & 5 & 10 & 12 & 28 \\
Kaliwungu & 0 & 2 & 3 & 12 & 9 & 26 \\
Kaliwungu Selatan & 0 & 1 & 1 & 3 & 18 & 23 \\
Kangkung & 0 & 2 & 4 & 2 & 10 & 18 \\
Kota Kendal & 2 & 5 & 7 & 6 & 7 & 27 \\
Limbangan & 1 & 9 & 6 & 7 & 11 & 34 \\
Ngampel & 4 & 6 & 11 & 6 & 3 & 30 \\
Pageruyung & 0 & 0 & 3 & 6 & 8 & 17 \\
Patean & 7 & 8 & 11 & 4 & 0 & 30 \\
Patebon & 0 & 7 & 14 & 10 & 1 & 32 \\
Pegandon & 3 & 4 & 3 & 11 & 9 & 30 \\
Plantungan & 0 & 0 & 3 & 7 & 9 & 19 \\
Ringinarum & 10 & 8 & 4 & 3 & 1 & 26 \\
Rowosari & 1 & 3 & 7 & 2 & 6 & 19 \\
Singorojo & 2 & 1 & 11 & 10 & 3 & 27 \\
Sukorejo & 4 & 5 & 9 & 10 & 8 & 36 \\
Weleri & 1 & 10 & 11 & 10 & 2 & 34 \\
\hline Total & 1 & 2 & 7 & 8 & 12 & 30 \\
\hline
\end{tabular}

Sumber data: Diolah dari Dapodikdasmen, 2019.

Dalam diskusi juga mencul berbagai kelebihan dan kekurang sekolah setelah digabung. Salah satunya adalah menyatukan iklim sekolah yang tidak mudah. Dampak positif penggabungan adalah proses pembelajaran dan kegiatan lainnya dapat berjalan dengan baik karena guru dan sarpras pendidikan semakin lengkap. Tapi salah satu dampat negatifnya adalah adanya rasa minder dari wali siswa yang kurang mampu karena latar belakang enonomi yang berbeda (Habiby, Tetrasari, Maldinni, dan Pratiwi et al., 2018). Hasil penelitian lain menunjukkan bahwa terjadi hambatan yang berasal dari paguyuban kelas karena belum memahami tujuan penggabungan (Ferina dan Setyowati, 2018). Proses Penggabungan selalu ada pro dan kontra diantara stakeholder pendidikan (Attaqwa, 2018). Dalam proses penggabungan sekolah jug terjadi transisi budaya sehingga terjadi krisis identitas, zona netral, dan proses pembangungan identitas (Octavia, Ulfatin, dan Arifin, 2018).

\section{Kondisi Guru SDN di Kabupaten Kendal}

Analisis terhadap kondisi guru dilaksanakan pada tanggal 17 September 2019 di Aula Dinas Pendidikan Kabupaten Kendal seperti tampak pada gambar 3.

Total guru di Kabupaten Kendal sebanyak 5.452 orang dengan rincian guru kelas 3.471 orang, guru mata pelajaran 1.410 orang, dan kepala sekolah 571 orang. Ditinjau dari status kepegawaian, sebanyak 3.576 orang atau 66\% berstatus PNS dan 1.876 orang atau 34\% berstatus non PNS. Selengkapnya dapat dilihat pada tabel 3 . 


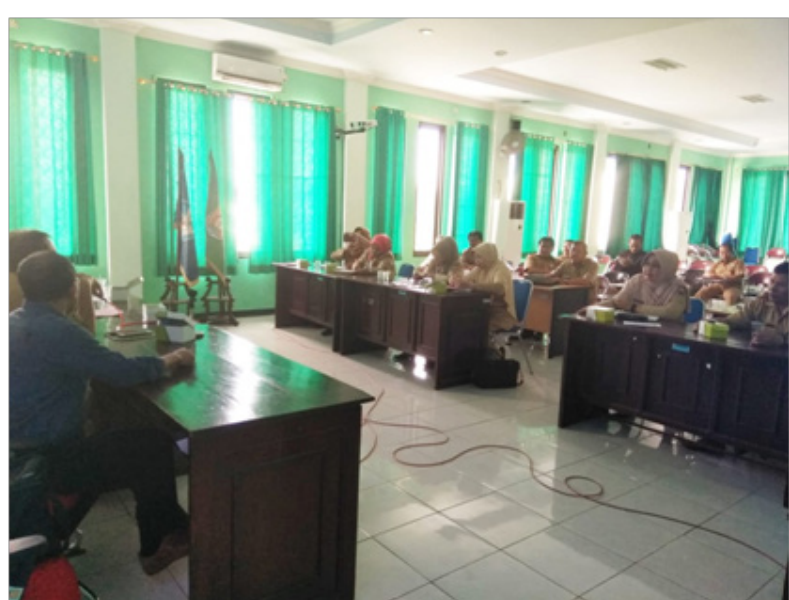

Gambar 3. Analisis Kondisi Guru di Kabupaten Kendal

Perbandingan jumlah guru kelas dengan rombongan belajar akan menunjukkan kecukupan guru. Jika perbandingan guru kelas dengan jumlah rombongan belajar kurang dari 1 berarti kekurangan guru kelas. Jika rasio guru kelas dengan jumlah rombel lebih dari 1 berarti kelibihan guru kelas. Selengkapnya dapat dilihat pada tabel 4 .

Tabel 4 menunjukkan bahwa jumlah guru kelas baik PNS maupun non PNS lebih banyak dibandingkan dengan kebutuhan, hal ini terjadi pada 404 sekolah atau $73 \%$ SDN, sementara itu ada 39 sekolah atau 7\% yang kekurangan guru kelas. Hanya ada 108 atau 20\% sekolah yang antara kebutuhan dan pemenuhan guru kelas adalah 1.

Tabel 3. Kondisi Guru Di Kabupaten Kendal

\begin{tabular}{ccccc}
\hline Status & $\begin{array}{c}\text { Guru } \\
\text { Kelas }\end{array}$ & $\begin{array}{c}\text { Guru } \\
\text { Mapel }\end{array}$ & $\begin{array}{c}\text { Kepala } \\
\text { Sekolah }\end{array}$ & Jumlah \\
\hline Non PNS & 1.450 & 406 & 20 & 1.876 \\
PNS & 2.021 & 1.004 & 551 & 3.576 \\
\hline Total & 3.471 & 1.410 & 571 & 5.452 \\
\hline
\end{tabular}

Sumber data: Diolah dari Dapodikdasmen, 2019.

Tabel 4. Kecukupan Guru Kelas

\begin{tabular}{ccc}
\hline Kecukupan & Jumlah & Persen \\
\hline Rasio $<1$ & 39 & $7 \%$ \\
Rasio 1 & 108 & $20 \%$ \\
Rasio $>1$ & 404 & $73 \%$ \\
\hline Total & 551 & $100 \%$ \\
\hline
\end{tabular}

Sumber data: Diolah dari Dapodikdasmen, 2019.
Guru PNS sebanyak 3.576 orang tersebut akan pensiun dalam kurun waktu 10 tahun ke depan sebanyak 2.239 orang atau $63 \%$ dan yang akan pensiun 20 tahun mendatang sebanyak 969 orang atau 18\%. Artinya selama 20 tahun ke depan guru SDN yang akan pensiun mencapai $81 \%$. Jika tidak ada pengangkatan secara berkelanjutan maka guru SDN selama 20 tahun mendatang hanya tinggal 19\% guru PNS dan dipastikan layanan pendidikan tidak berjalan secara maksimal.

Jika diperhatikan dari status sertifikasi, sebanyak 3.250 orang sudah mendapatkan tunjangan sertifikasi dan sebanyak 2.202 orang belum mendapatkan tunjangan sertifikasi. Hal ini dapat dilihat pada tabel 5.

Jika dilihat berdasarkan kualifikasi akademik guru, sebanyak 4.811 orang atau $88 \%$ telah memenuhi kualifikasi akademik S1 atau D4. Sementara itu sebanyak 641 orang atau 12\% belum memenuhi kualifikasi akademik S1 atau D4. Selengkapnya dapat dilihat pada tabel 6.

Tabel 5. Status Sertifikasi Guru

\begin{tabular}{lccc}
\hline \multicolumn{1}{c}{$\begin{array}{c}\text { Status } \\
\text { Kepegawaian }\end{array}$} & $\begin{array}{c}\text { Belum } \\
\text { Sertifikasi }\end{array}$ & $\begin{array}{c}\text { Sudah } \\
\text { Sertifikasi }\end{array}$ & Jumlah \\
\hline CPNS & 6 & 3 & 9 \\
GTY/PTY & 209 & 40 & 249 \\
Honor & 1.377 & 3 & 1.380 \\
Sekolah & & & \\
Honda Prov. & 3 & 0 & 3 \\
Honda Kab. & 217 & 27 & 244 \\
PNS & 388 & 3.161 & 3.549 \\
PNS Depag & 2 & 12 & 14 \\
PNS & 0 & 4 & 4 \\
Perbantukan & \multicolumn{4}{c}{ Total } & 2.202 & 3.250 & 5.452 \\
\hline \multicolumn{2}{c}{ Sumber data: Diolah dari Dapodikdasmen, 2019.}
\end{tabular}

Tabel 6. Guru Memenuhi Kualifikasi Akademik

\begin{tabular}{ccccc}
\hline $\begin{array}{c}\text { Kualifikasi } \\
\text { Akademik }\end{array}$ & $\begin{array}{c}\text { Guru } \\
\text { Kelas }\end{array}$ & $\begin{array}{c}\text { Guru } \\
\text { Mapel }\end{array}$ & $\begin{array}{c}\text { Kepala } \\
\text { Sekolah }\end{array}$ & Jumlah \\
\hline Belum S1 & 384 & 243 & 14 & 641 \\
Sudah S1 & 3.087 & 1.167 & 557 & 4.811 \\
\hline Total & 3.471 & 1.410 & 571 & 5.452 \\
\hline
\end{tabular}

Sumber data: Diolah dari Dapodikdasmen, 2019. 
Muhdi, dkk - Penggabungan Sekolah Dasar Negeri di Kabupaten Kendal ...

Tabel 7. Sertifikasi Guru Vs Pelajaran Diampu

\begin{tabular}{ccccc}
\hline Sertifikasi & $\begin{array}{c}\text { Tidak } \\
\text { Sesuai }\end{array}$ & Sesuai & N/A & Jumlah \\
\hline $\begin{array}{c}\text { Belum } \\
\text { Sertifikasi } \\
\text { Sudah } \\
\text { Sertifikasi }\end{array}$ & 0 & 0 & 2.202 & 2.202 \\
\hline Total & 509 & 2.741 & 0 & 3.250 \\
\hline
\end{tabular}

Sumber data: Diolah dari Dapodikdasmen, 2019.

Bila kita telusur lebih dalam lagi guru yang belum memenuhi kualifikasi akademik S1 atau D4 dan masih memiliki masa kerja > 10 tahun sebanyak 327 orang. Sebanyak 55 orang berstatus PNS dan 272 orang berstatus non PNS.

Berdasarkan data total guru yang sudah menerima tunjangan sertifikasi yaitu sebanyak 3.250 , sebanyak 734 orang atau $23 \%$ belum memenuhi beban mengajar 40 jam per minggu, sebanyak 2.516 atau $77 \%$ sudah memenuhi beban mengajar 40 jam per minggu.

Total guru SDN yang sudah bersertifikasi sebanyak 3.250 orang. Jika dicermati sertifikasi guru dibandingkan dengan mata pelajaran yang diampu, ternyata ditemukan banyak guru yang mengajar tidak sesuai dengan sertifikasinya yaitu sebanyak 509 orang atau 16\%. Berarti sebanyak 2.741 guru atau $84 \%$ yang sudah sertifikasi mengajar sesuai antara pelajaran sertifikasi dengan pelajaran yang diampu saat ini. Hal ini dapat dilihat pada tabel 7.

Berdasarkan data Neraca Pendidikan Daerah (NPD) tahun 2018, kompetensi guru SD di Kabupaten Kendal mencapai 61,44 yang artinya lebih rencah dari kompetensi guru SD di Provinsi Jawa Tengah yang mencapai 61,88. Jika dibandingkan dengan target nasional tahun 2018 seperti yang tertuang dalam RPJMN 20152019 kompetensi guru SD harus mencapa 70, maka kompetensi guru SD di Kabupaten Kendal masih jauh dari target nasional.

\section{Efisiensi Pengelolaan SDN di Kabupaten Kendal}

Efisiensi pengelolaan sekolah di Kabupaten Kendal dapat dilihat dari beberapa aspek yaitu jumlah murid per sekolah, rasio guru dibanding siswa, rasio ruang kelas dibanding rombongan belajar, kecukupan guru kelas, dan beban mengajar guru.

Salah satu kriteria untuk mengukur efisiensi sekolah adalah dilihat dari perbandingan antara jumlah murid dan guru. Di beberapa negara, ukuran perbandingan guru dan jumlah siswa adalah 1:20 artinya jika seorang guru menangani $<20$ siswa tidak efisien sebaliknya jika seorang guru menangani $>20$ siswa efisien. Ukuran ini penting dalam pengelolaan pendidikan agar pemanfaatan sumber daya pendidikan bisa efisien dan efektif.

Di Kabupaten Kendal juga sudah diatur dalam Perda Pendidikan No. 4 Tahun 2018 bahwa perbandingan guru dengan peserta didik pada jenjang SD atau yang setara adalah 1:20. Rasio guru dengan murid SDN di Kabupaten Kendal dapat dilihat pada tabel 8.

Tabel 8 menunjukkan bahwa sebagian besar sekolah belum dilaksanakan secara efisien yaitu sebanyak $76 \%$, sementara yang telah dilaksanakan secara efisien berdasarkan rasio guru siswa hanya $24 \%$ saja.

Penyediaan sarana dan prasarana sekolah juga menjadi ukuran efisiensi sekolah. Salah satu yang bisa dilihat adalah ketersediaan ruang kelas dibanding dengan jumlah rombongan belajar. Jika ketersediaan ruang belajar kurang dari 1 artinya ada kelas yang digunakan lebih dari 1 rombongan belajar dan hal ini tidak efefktif untuk mencapai tujuan pendidikan. Jika rasio ruang kelas lebih dari 1 artinya ada ruang kelas yang tidak digunakan karena ketersediaan ruang kelas lebih banyak dibanding yang dibutuhkan. Perbandingan ruang kelas dan jumlah rombel dapat dilihat pada tabel 9.

Data pada tabel 9 menunjukkan sudah banyak ruang kelas yang telah digunakan secara efisien yaitu $88 \%$, hanya ada $12 \%$ ruang kelas yang tidak efisien karena kekurangan atau kelebihan.

Tabel 8. Rasio Guru dan Murid

\begin{tabular}{ccc}
\hline Rasio Murid/Guru & Jumlah & Persen \\
\hline Rasio $<=10$ & 52 & $9 \%$ \\
Rasio $11-20$ & 368 & $67 \%$ \\
Rasio $>20$ & 131 & $24 \%$ \\
\hline Total & 551 & $100 \%$ \\
\hline
\end{tabular}

Sumber data: Diolah dari Dapodikdasmen, 2019. 
Tabel 9. Rasio Ruang Kelas dan Rombel

\begin{tabular}{ccc}
\hline Rasio Ruang/Rombel & Jumlah & Persen \\
\hline Rasio $<1$ & 30 & $5 \%$ \\
Rasio 1 & 483 & $88 \%$ \\
Rasio $>1$ & 38 & $7 \%$ \\
\hline Total & 551 & $100 \%$ \\
\hline
\end{tabular}

Sumber data: Diolah dari Dapodikdasmen, 2019.

Perbandingan guru kelas dengan jumlah rombongan juga terjadi ketidakefisienan karena di 404 SDN atau 73\% kelebihan guru kelas, hanya ada di 39 SDN atau 7\% yang kekurangan guru kelas. Sedangkan di 108 SDN atau 20\% perbandingan antara kebutuhan guru kelas dengan rombongan belasa adalah 1 .

Beban kerja guru adalah salah satu ukuran efisiensi sekolah. Indikator ini membandingkan antara gaji dan tunjungan yang dibayarkan kepada guru dengan beban kerja guru. Ukurannya adalah mengacu pada peraturan pemerintah yaitu minimal 40 jam per minggu. Jika guru belum memenuhi beban kerja minimal tersebut berarti belum efisien, sebaliknya jika guru sudah memenuhi beban kerja maka sudah efisien.

Pada Peraturan Pemerintah Nomor 74 tahun 2008 tentang Guru diatur pada Bab IV Pasal 52 ayat (2) bahwa beban kerja guru minimal 24 jam tatap muka dan maksimal 40 jam tatap muka per minggu. PP tersebut telah diperbaharui melalui Peraturan Pemerintah Nomor 19 tahun 2017 namun bunyi pasal 52 masih sama. Pada ayat 1 disebutkan bahwa beban kerja guru mencakup kegiatan pokok merencanakan pembelajaran, melaksanakan pembelajaran, menilai hasil pembelajaran, membimbing dan melatih peserta didik, serta melaksanakan tugas tambahan. Rekapitulasi beban kerja guru SDN di Kabupaten Kendal dapat dilihat pada tabel 10.

Tabel 10. Beban Mengajar Guru SDN

\begin{tabular}{ccccc}
\hline Sertifikasi & Kurang & Sesuai & Lebih & Jumlah \\
\hline Belum & 398 & 1.765 & 39 & 2.202 \\
Sudah & 734 & 2.480 & 36 & 3.250 \\
\hline Total & 1.132 & 4.245 & 75 & 5.452 \\
\hline
\end{tabular}

Sumber data: Diolah dari Dapodikdasmen, 2019.
Berdasarkan data pada tabel 10, disimpulkan bahwa beban kerja guru sebagian besar atau 79\% sudah efisien karena sudah sesuai dengan beban kerjanya. Hanya 21\% saja guru yang belum bekerja sesuai dengan beban kerja yang ditentukan.

Namun jika dibandingkan antara guru yang sudah sertifikasi dan belum sertifikasi, prosentase guru yang telah sertifikasi namum belum mengajar sesuai dengan beban kerja lebih tinggi dibandingkan dengan guru yang belum sertifikasi yaitu $23 \%>18 \%$. Hal ini menunjukkan bahwa guru sertifikasi yang menerima gaji pokok dua kali lipat banyak yang belum mengajar sesuai dengan beban kerja yang telah ditentukan.

Beberapa penelitian terkait penggabungan sekolan menunjukkan bahwa setelah digabung sekolah menjadi semakin efisien. Bahwa setelah dilakukan penggabungan terjadi efisiensi dalam mengalokasiann guru dan fasilitas sekolah (Erowati, Slameto, dan Wasitohadi, 2018). Penelitian lain hasilnya menunjukkan bahwa penggunanan dana pendidikan dan fasilitas sekolah menjadi lebih efisien (Alnet; Sulasmono, 2019). Hasil penelitian serupa menunjukkan bahwa penggabungan telah meningkatkan efisiensi gaji guru dan pegawai, meninggakan kelengkapan sarpras, dan pemanfaatan sarpras sekolah (Wigatiningrum dan Alip, 2015).

Setelah dilakukan penggabungan pengelolaan pendidikan tidak hanya efisien tatapi juga efektif. Hal ini ditunjukkan oleh (Indrayani, 2013). Efektivitas juga ditunjukkan pada manajemen pembelajaran, kesiswaan, pepegawaian, sarpras, keuangan, hubungan masyarakat, dan manajemen layanan khusus. Hasil penelitian serupa oleh (Setiawati, 2018) bahwa penggabungan sekolah buka hanya miningkatkan efisiensi, tapi juga efektivitas dalam proses pembelajaran, kinerja guru dan kepada sekolah, meningkatkan motivasi kerja guru dan kepala sekolah, bahwa meningkatkan partisipasi komite sekolah. Setelah sekolah digabung perlu disusun kebijakan budaya mutu secara besama-sama antara kepala sekolah, guru, pegawai, komite sekolah, dan dinas pendidikan (Maharani, 2017). 


\section{SIMPULAN}

Kondisi satuan pendidikan tidak merata karena mayoritas (71\%) SDN di Kabupaten Kendal termasuk katetori sekolah sangat kecil (44\%) dan sekolah kecil (27\%). Di dalam sekolah kategori sangat kecil terdapat 37 sekolah yang jumlah muridnya $\leq 60$ orang yang menjadi prioritas ke-1 untuk digabung. Terdapat 138 sekolah sangat kecil prioritas ke-2 untuk digabung yaitu jumlah murid 61-90 orang.

Kondisi guru kelas mengalami kelebihan di $73 \%$ SDN, guru PNS mendominasi yaitu 66\%, dan sebanyak $88 \%$ guru SDN telah memenuhi kualifikasi akademik S1 atau D4. Guru penerima tunjangan sertifikasi yaitu sebanyak 3.250 orang namun $23 \%$ diantaranya belum memenuhi beban mengajar 40 jam per minggu.

Pengelolaan SDN di Kabupaten Kendal belum efisien. Hal ini dapat dilihat dari rasio guru siswa yang tidak efisien karena $76 \%$ sekolah belum memiliki perbandingan guru dengan siswa 1:20. Perbandingan guru kelas dengan rombongan belajar juga tidak efisien karena ada 404 sekolah atau 73\% SDN yang kelebihan guru kelas. Dilihat dari beban kerja guru sebanyak $21 \%$ guru belum bekerja sesuai dengan beban kerja yaitu 40 jam per minggu. Namun demikian dilihat dari rasio ruang kelas dengan rombongan belajar sudah efisien karena 88\% sekolah telah memenuhi rasio 1:1.

Berdasarkan simpulan di atas beberapa saran yang diberikan dalam artikel ini adalah sebagai berikut. Pertama, segera dilakukan penggabungan sekolah terutama untuk sekolahsekolah sangat kecil. Oleh karena itu perlu segera diatur dalam Perda atau Perbub tentang penggabungan sekolah tanpa mengabaikan akses pendidikan dan demi efisiensi pengelolaan pendidikan. Luaran pengabdian kepada masyarakat ini berupa draf peraturan bupati dapat ditindaklanjuti menjadi kebijakan yang legal formal.

Kedua, perlu merekomendasikan atau mengajukan usulan ke Pemerintah Pusat untuk melakukan pengangkatan guru SD dalam jumlah besar selama kurun waktu 10 tahun mendatang agar tidak mengalami kesulitan operasional pembelajaran. Jika Pemerintah Pusat masih mengalami kesulitan keuangan maka Pemerintah Kabupaten Kendal perlu mengalokasikan gaji sesuai UMR di APBD nya untuk pengangkatan guru-guru Honorer Daerah Kabupaten.

Ketiga, perlu dilakukan monitoring dan evaluasi beban kerja guru karena masih banyak guru yang belum memenuhi beban kerja, terutama para guru penerima tungjangan profesi. Monitoring dan evaluasi juga penting untuk dilakukan terhadap keberadaan guru kelas baik PNS dan non PNS, karena keberadaan guru kelas melebihi kebutuhan. Pengelolaan aset sekolah juga perlu dievaluasi, jangan sampai ada aset sekolah yang tidak terpakai sehingga terjadi pemborongan atau tidak efisien.

\section{PERSANTUNAN}

Terimakasih Kepada Dinas Pendidikan dan Kebudayaan Kabupaten Kendal yang bersedia memberikan data dan memfasitasi pertemuanpertemuan sehingga proses ferivikasi data dan diskusi dalam pengabdian kepada masyarakat ini dapat berjalan dengan lancar dan produktif.

\section{DAFTAR PUSTAKA}

Alnet, P. M.; Sulasmono, B. S. (2019). The Evaluation Of Regrouping Program In State Elementary School. Elementary, 5, N. 2, P. 117-126, 2019.

Attaqwa, M. H. (2018). Implementasi Merger Sekolah Di SMKN 12 Surabaya. Jurnal Manajemen Pendidikan, 6, N. 3, P. 1-8, 2018.

Bank Dunia. (2013). Mendayagunakan Guru dengan Lebih Baik: Memperkuat Manajemen Guru untuk Meningkatkan Efisiensi dan Manfaat Belanja Publik, Naskah Kebijakan 74155.

Dwiningrum, S. I. A.; Widiowati, R. (2014). School Resiliency And Social Capital Ff Regrouping Policy After Merapi Eruption In The Special District Of Yogyakarta Of Indonesia (A Case Study At Sd 
Muhdi, dkk - Penggabungan Sekolah Dasar Negeri di Kabupaten Kendal ...

Umbulharjo 2, Sleman, Special District Of Yogyakarta). International Journal of Asian Social Science, 4, N. 4, P. 510-525, 2014.

Dapodikdasmen Semester Gasal 2018-2019 yang diunduh tanggal 8 Januari 2019, www.dapo. dikdasmen.mendikbud.go.id.

Erowati, M. T.; Slameto; Wasitohadi. (2018). Evaluasi Program Regrouping Sekolah Dasar Negeri. Kelola - Jurnal Manajemen Pendidikan, 5, n. 2, p. 152-164, 2018.

Ferina, T. G.; Setyowati, S. (2018). Implementasi Kebijakan Regrouping (Studi Kasus di SD Negeri Banjarsari 1 Kecamatan Trucuk Kabupaten Bojonegoro). Jurnal Manajemen Pendidikan, 6, n. 1, p. 1-8, 2018.

Habiby, W. N.; Tetrasari, A.; Maldinni, R.; Pratiwi, I. N. et al. (2018). Dinamika Merger Sekolah: Antara Pengembangan Dan Problem Sekolah. Profesi Pendidikan Dasar, 1, n. 2, p. 177-184, 2018.

Indrayani, L. (2013). Efektivitas Implementasi Regrouping Sekolah Dasar Di SD N0. 2 Banjar Tegal Kecamatan Buleleng. Ekuitas - Jurnal Pendidikan Ekonomi, 1, n. 1, p. 77-85, Desember 2013.

Kepmendiknas Nomor 060/U/2002 tentang Pedoman Pendirian Sekolah.

Kepmendagri Nomor 421.2/2501/bangda, 1998. Pedoman Pelaksanaan Penggabungan (Regrouping) Sekolah Dasar, Jakarta, 16 Nopember 1998.

Maharani, N. L. (2017). Kebijakan Sekolah Dalam Mengembangkan Budaya Mutu Pada Sekolah Regroupingdi SDN Ungaran 1 Yogyakarta. Jurnal Kebijakan Pendidikan, VI, n. 3, p. 275-288, 2017.

Neraca Pendidikan Daerah 2018, www.kemdikbud.go.id.

Octavia, L. S.; Ulfatin, N.; Arifin, I. (2018). Proses Transisi Budaya Organisasi pada Sekolah Regrouping. Jurnal Pendidikan: Teori, Penelitian, dan Pengembangan, 3, n. 11, p. 1405-1410, November 2018.

Perda Pendidikan No. 4 Tahun 2018 tentang Perubahan atas Peraturan Daerah Kabupaten Kendal Nomor 10 Tahun 2012 tentang Pengelolaan dan Penyelenggaraan Pendidikan di Kabupaten Kendal.

Permendiknas Nomor 24 Tahun 2007 tentang Standar Sarpras Pendidikan dasar dan Menengah.

Peraturan Pemerintah Nomor 74 Tahun 2008 tentang Guru, Lembaran Negara Republik Indonesia Tahun 2008 Nomor 194, Tambahan Lembaran Negara Republik Indonesia Nomor 4941.

Peraturan Pemerintah Nomor 19 Tahun 1017 tentang Perubahan atas Peraturan Pemerintah Nomor 74 Tahun 2008 tentang Guru, Penjelasan dalam Tambahan Lembaran Negara Republik Indonesia Nomor 6058.

Purwaningsih, I. (2014). Implementasi Kebijakan Regrouping Sekolah Dasar di Kabupaten Purworejo. Skripsi: Universitas Negeri Yogyakarta.

Rencana Pembangunan Jangka Menengah Nasional Tahun 2016-2019.

Rencana Strategis Dinas Pendidikan Kabupaten Kendal Tahun 2016-2021.

Setiawati, T. (2018). Program Penggabungan Sekolah Dasar (SD) Dalam Meningkatkan Efektivitas dan Efisiensi Penyelenggaraan Pendidikan. MENDIDIK: Jurnal Kajian Pendidikan dan Pengajaran, 4, n. 1, p. 55-62, 2018.

Sudiyono, Sutapa M, dan Purwanto, NA. (2009). Dampak Regrouping Sekolah Dasar Kasus SD Pakem 1 di Kecamatan Pakem Kabupaten Sleman. Laporan Penelitian Kelompok FIP UNY.

Triwiyanto, T. (2017). Regrouping of Schools Within One Complex and Teacher Redistribution to Attain Equitable Management and Distribution of Teachers. Atlantis Press, 2017. 13-18 p. (2nd International Conference on Educational Management and Administration (CoEMA 2017), v. 45). 
Muhdi, dkk - Penggabungan Sekolah Dasar Negeri di Kabupaten Kendal ...

Wigatiningrum, D. N.; Alip, M. (2015). Keefektifan Penggabungan Sekolah Dasar Di Kecamatan Bambanglipuro Bantul. Jurnal Akuntabilitas Manajemen Pendidikan, 3, n. 1, p. 13-23, 2015. 